Revista do SELL

V. 5 , no. 1

ISSN: $1983-3873$

\title{
A PRESSUPOSIÇÃO COMO ARTIFÍCIO PERSUASIVO NAS PUBLICIDADES DA TIXAN
}

\section{THE AS ASSUMPTION PERSUASIVE FIREWORKS IN ADVERTISEMENTS OF TIXAN}

\author{
Juliana Lopes Melo Ferreira Sabino \\ Pontifícia Universidade Católica de Minas Gerais
}

\section{Resumo}

Partindo da hipótese de que a pressuposição é explorada na produção de sentido em peças publicitárias, o presente artigo tem como objetivo analisar três publicidades da Tixan: (i) o poder da mulher de ler pensamentos; (ii) o poder da mulher de persuasão; e (iii) o poder da mulher de multiplicação, as quais serão analisadas sob a ótica da pressuposição de Ducrot $(1972,1978)$, Mari (2015) e outros autores que citaremos ao longo deste estudo. A tentativa é de evidenciar em que medida as publicidades exploram a categoria da pressuposição para provocar o efeito de sentido pretendido pela empresa. Buscar-seá, assim, apresentar a descrição das propagandas e explicar, à luz da Teoria Semântica, como o sentido é construído.

Palavras-chave: Pressuposição; Publicidade; Semântica.

\begin{abstract}
Assuming that the assumption is exploited in the production of meaning in advertisements, this article aims to analyze three advertisements of Tixan: (i) the power of women to read minds; (ii) the power of persuasion woman; and (iii) the power of multiplication woman, which will be analyzed from the perspective of assumption Ducrot (1972, 1978), Mari (2015) and other authors who will cite throughout this study. The attempt is to highlight the extent to which advertising explore the category of assumption to cause the effect of the sense intended by the company. Search It will thus provide a description of the advertisements and explain, in the light of Semantic Theory, as the meaning is constructed.
\end{abstract}

Keywords: assumption; advertising; Semantics. 


\section{Introdução}

A cada dia, as pessoas são bombardeadas pela mídia, oral ou escrita, com propagandas e publicidades que visam atingir vários objetivos, como emocionar e seduzir o telespectador. A televisão de canal aberto consiste, no contexto do século XXI, no mais importante meio técnico de comunicação em uso no Brasil e é o principal instrumento de comunicação de nosso tempo.

Mesmo com a exclusão social de milhões de pessoas, nos mais diversos níveis e situações, nas últimas décadas, houve o barateamento relativo e a facilidade de se adquirir esse eletrodoméstico. Pela televisão, as empresas e os governos demonstram interesse em ter como se dirigir à população, do mesmo modo e ao mesmo tempo. Desde sua origem, há cinquenta anos, ela é comandada por empresas privadas que a vislumbraram, inicialmente, como uma fonte de lucratividade baseada nos anúncios publicitários privados e públicos.

A televisão veicula um conjunto impressionante de informações, argumentos, emoções e preferências que dialogam cotidianamente com a população brasileira. Esse conjunto influencia, sistematicamente, há pelo menos quarenta anos, as culturas e comportamentos médios das pessoas que compõem esta nação. Pode-se dizer, assim, que ela foi muito mais longe que a rádio em seu poder e alcance.

As agências de publicidade lançam mão de vários recursos para que o texto, então veiculado, torne-se agradável. Bolinger (apud CARVALHO, 2003, p. 18) postula a respeito da linguagem publicitária, que: "com o uso de simples palavras, a publicidade pode transformar um relógio em jóia, um carro em um símbolo de prestígio e um pântano em paraíso tropical”. Assim, a linguagem e o poder persuasivo operado pela mídia, em especial, a publicitária televisiva, utiliza-se de recursos variados, como estéticos, expressivos e apelativos, no intuito de manipular e persuadir o sujeito destinatário (telespectador) para adquirir o produto Tixan.

Por conseguinte, quando um produtor faz sua escolha, é levado em conta o produto anunciado, o suporte em que será veiculada a mensagem, os interlocutores envolvidos, enfim, toda a cena enunciativa, isto é, as condições 
de produção do gênero. Desconsiderá-las no processo de elaboração dos textos publicitários provocaria uma interpretação fragmentada.

A publicidade é um dos gêneros discursivos veiculados pela televisão e que atinge um público variado de todas as classes sociais. Ela é definida como expressão de opinião ou ação por parte de indivíduo ou grupos, deliberadamente destinada a influenciar opiniões ou ações de outros indivíduos ou grupos relativamente a fins predeterminados.

Acreditamos que a pressuposição está atrelada à persuasão das três publicidades ora propostas para a análise neste artigo, visto que ela é um dos elementos que constitui o sentido das publicidades. Podemos perceber que, nas três publicidades que iremos analisar, intenta-se a atingir um elevado nível de persuasão, haja vista a ação provocada, a do consumo. Nesse sentido, o que o publicitário intenta é que a persuasão atinja o seu objetivo maior - a adesão do consumidor da ideia expressa na publicidade e, consequentemente, a compra do produto anunciado. A partir desse artifício da persuasão, a tentativa é levar o outro a aceitar o que está sendo dito, ou seja, os valores sedimentados da Tixan.

Ao ser construído, o texto publicitário tem como objetivo-alvo persuadir o outro, e para isso, seleciona cada palavra, imagem, som, na tentativa de criar um meio para alcançar esse objetivo. Vale lembrar que, essa escolha não é arbitrária, ao contrário, é fruto de uma atitude ideológica. Como poderemos observar mais adiante, na análise, a pressuposição é um recurso que subsidia a persuasão, por ser um recurso argumentativo.

Dessa forma, tomaremos como objeto de estudo três publicidades da Tixan, as quais:

Publicidade 1: Tixan Ipê apresenta: o poder da mulher de ler pensamentos;

Publicidade 2: Tixan Ipê apresenta: o poder da mulher de persuasão;

Publicidade 3: Tixan Ipê apresenta: o poder da mulher de multiplicação.

As publicidades elencadas acima serão analisadas sob o olhar da pressuposição de Ducrot (1972, 1978), Mari (2015) e outros autores que citaremos ao longo deste estudo. A seguir, tratar-se-á dos conceitos de sentido e referente, 
bem como as noções de pressuposição, o que contribuirá para sustentar nossa análise.

\section{Arcabouço teórico}

Uma pesquisa que se dedique a investigar o processo de significação demanda, primeiramente, a definição das categorias que serão tomadas como instrumento de análise. Nesse sentido, os postulados de Gottlob Frege (1978) têm importante contribuição, pois apresentam conceitos basilares e discussões que orientaram o estudo sobre o sentido.

Em um de seus trabalhos, Frege (1978), ao discutir a relação que existe entre sentido e referente, afirma que o entendimento do sentido de um sinal implica a familiarização dos interlocutores com a linguagem ou com os objetos que ele designa. A produção de sentido passa, então, pela percepção humana e pode ser compreendida como fruto da relação entre referência e representação que se tem de um sinal.

Frege (1978, p.64) explica que a referência consiste num objeto sensorialmente perceptível, isto é, naquilo que é designado pelo sinal, enquanto a representação é "a imagem interna, emersa das lembranças de impressões sensíveis passadas e das atividades, internas e externas" realizadas pelo indivíduo. Um biólogo, um alérgico e um nutricionista, por exemplo, teriam representações diferentes do substantivo pólen. Como se percebe, a representação é algo subjetivo e, portanto, pode variar de pessoa para pessoa.

Frege (1978) ressalta que existem afinidades ou semelhanças entre as representações humanas, o que torna possível, por exemplo, a interpretação da arte poética. Nessa medida, é possível entender o sentido de um enunciado porque se evocam, a partir do referente/das sugestões dadas pelo enunciador, as representações de um determinado sinal.

Frege (1978) destaca ainda que, para se afirmar que uma sentença faz sentido, somos impelidos a julgar o seu valor de verdade. Dessa forma, "o pensamento perde o valor para nós tão logo reconhecemos que a referência de uma de suas partes está faltando" (FREGE, 1978, p.68), isto é, se nos falta à 
referência de uma das partes do enunciado, o sentido não é construído, pois não se pode passar o seu conteúdo pelo crivo do verdadeiro ou falso.

A busca pela verdade, conforme salienta Frege (1978), é que nos conduz do sentido para a referência. É preciso, pois, que haja a compreensão do que se trata a referência, se ela é verdadeira ou não, para que se produza sentido. Nessa medida, pode-se considerar que o sentido consiste no valor de verdade construído a partir da relação entre referente e representação. Vale salientar que a verdade aqui pode ser entendida como a certificação de que o ato enunciado tem condições para ser bem-sucedido, isto é, para ser realizado.

Sendo a pressuposição parte do processo da produção de sentido, é importante elucidar a forma como alguns teóricos a concebem, pois se trata de uma categoria cara para esse campo de estudo. De acordo com Keenan (1971), a pressuposição consiste nas condições encontradas para que uma sentença faça sentido. Ele, porém, desdobra essa categoria em dois tipos, a fim de esclarecer com mais precisão esse conceito geral. Segundo ele, a pressuposição lógica pode ser definida a partir da seguinte relação: uma sentença $S$ logicamente pressupõe uma sentença $S 1$ se $S$ implicar $S 1$ e a negação de $S$, ou seja, $\neg S$ também implicar $S 1$. Ela é concebida, então, a partir de dois conceitos da lógica matemática: verdade e consequência lógica.

Já a pressuposição pragmática é definida pela relação entre o enunciado da sentença e o contexto, isto é, as relações que são estabelecidas entre os interlocutores e, até mesmo, os objetos físicos que fazem parte da cena enunciativa. Dessa forma, indagar "Você não está com calor?" pode pressupor alguém que deseja o consentimento de outrem para ligar o ventilador num ambiente em que ele esteja desligado.

A pressuposição exerce um papel relevante na língua e que segundo Ducrot "pressupor não é dizer o que o ouvinte sabe ou o que se pensa que ele sabe ou deveria saber, mas situar o diálogo na hipótese de que ele já soubesse" (DUCROT, 1972, p.77). (MARI, 2015, p.1) pontua que a "Pressuposição é quase sempre referida como um processo que permite deduzir certos fatos não-explicitados, a partir de outros que são explícitos; ou, então, o produto dessa operação". Para Frege (1972), no que se refere ao conceito de verdade, nos enunciados "as mulheres têm poderes, o poder de Tixan Ypê é um deles!" e "Tixan Ypê. Poderoso como você!" se o nome próprio 
composto "Tixan Ypê" tiver um valor-verdade (verdadeiro), logo as proposições "as mulheres têm poderes" e "Poderoso como você!" poderá ser verdadeiro ou falso. Conforme Mari (2015, p.2), em relação à pressuposição existencial, proposta por Frege, o fato de um objeto ser nomeável, por si só já adquire existência.

Segundo Strawson, 1952 (apud Mari, 2015) "Uma afirmação S pressupõe uma afirmação $S 1$ se, e somente se, a verdade de $S 1$ for uma precondição para a verdade ou para a falsidade de S." Assim, ao dizer os enunciados $S$ abaixo, pressupõem $S 1$ e S2, e que, (MARI, 2015, p.03), "significa dizer que a verdade de S1 é uma condição primeira (e necessária) para a verdade ou falsidade de $S$ ".

A partir da transcrição dos enunciados comuns às três publicidades, temos:

$\mathrm{S}=$ As mulheres têm poderes, o poder de Tixan Ypê é um deles!

$\mathrm{S} 1=$ Os homens não têm poderes. (PP)

S2 = As mulheres têm poderes além do Tixan Ypê. (PP)

$S=$ Tixan Ypê. Poderoso como você!

$\mathrm{S} 1=\mathrm{A}$ mulher é poderosa. $(\mathrm{PP})$

$\mathrm{S} 2$ = Somente as mulheres são poderosas. (PP)

Desse modo, se S1 e S2 são verdadeiros, logo S pode ser verdadeiro. Iremos retomar no quadro de análise essas reflexões de Strawson (1952) e Mari (2015) para elucidar um dos enunciados da publicidade categorizada como três.

Ainda sob o olhar da pressuposição pragmática, os sintagmas "As mulheres têm poderes, o poder de Tixan Ypê é um deles!" e "Tixan Ypê. Poderoso como você!" poderiam soar como fictícios, haja vista a relação entre o ato fala e o contexto - não existem "poderes", o que indicia o sobrenatural e também não há nada no produto demonstrável que revele um poder. Aqui poderíamos pensar que o enunciado foi proferido numa situação/universo infantil, dado o espaço da liberdade e criatividade, no entanto, vale ressaltar que essa interpretação poderia ser dada como verdade, considerando os 
recursos de que se valem as publicidades de modo geral a fim de atingir a persuasão.

Entre alguns dos tipos de pressupostos que Ducrot (1972) elenca, destacamos dois, os quais: o de construção, o qual corresponde à forma como é construída a frase - aqui é importante destacar o enunciado "Tixan Ypê. Poderoso como você!" que trás a frente o nome do produto na tentativa de evidenciá-lo, isto é, de trazê-lo como um espetáculo que já anuncia desde o início; e o adverbiais, introduzidas por morfemas como "ainda, já", dentre outros.

Ducrot (1978) pontua que as pressuposições possuem finalidades comunicativas. Elas podem estabelecer limites, direcionando o olhar/ o foco para uma dada situação. Outra questão sobre a pressuposição é a isenção da responsabilidade pelo que se diz em relação ao conteúdo pressuposto, isto é, dizer sem ser responsabilizado pelo dito e seus efeitos. E outra característica da pressuposição é justamente a sua capacidade de dizer de forma implícita uma verdade detrás da materialidade lingüística, e que é difícil de ser desconstruída.

Conforme Koch (2002, p.56), os conteúdos pressupostos são introduzidos por marcadores de pressuposição, e para ela "a noção de pressuposição constitui uma das noções basilares de toda a obra de Ducrot". O ato de pressuposição implica em uma organização interna do enunciado. Para Ducrot a função dos pressupostos, na manifestação da fala, é assegurar a coesão do discurso como condição de coerência.

Para este estudo, utilizaremos também os marcadores representados por meio dos verbos que indicam permanência de estado, como o da publicidade 1 "Tixan Ipê apresenta: o poder da mulher de ler pensamentos", em que o verbo "ler" está no presente, seu estado permanente, a de que a mulher sempre lê os pensamentos, produzindo um efeito de sentido, resultante do emprego além do verbo em questão, outros recursos linguísticos na construção do significado da publicidade. Este verbo no presente é aparentemente sem importância, porém pode induzir à compra do produto.

Passamos a seguir para a análise do corpus.

\section{Quadro de análise}


A tabela 1 apresenta a descrição das cenas enunciativas que compõem uma das peças publicitárias do sabão em pó Tixan Ypê, a partir do quadro teórico proposto por Sellars (1954) citado por Mari (2015), em que a pressuposição é definida como a atitude proposicional do falante frente a uma afirmação proferida. Assim, uma sentença $S$, corresponde tanto a $S^{1}$ como a $S^{2}$. Nesse sentido, de acordo com Mari (2015), se alguém enuncia a sentença $\mathrm{S}$, também assevera $\mathrm{S}^{1}$ e $\mathrm{S}^{2}$, conforme se observa no exemplo abaixo:

$\mathrm{S}$ = João parou fumar.

S1 = João fumava.

S2 = João não fuma mais.

Nesse exemplo, a asserção é o que se afirma em S2 (João fumava) e a pressuposição é "a atitude proposicional do falante em acreditar (estar convencido, estar certo) do conteúdo proposicional de S2." (MARI, 2015, p.04).

Descrição da pressuposição na publicidade-propaganda 2 "Tixan Ypê apresenta: O poder da mulher de Persuasão"

\section{Cena 1}

Ato de fala 1 (marido): Ter outro filho? Agora? Não, né?!

\section{Cena 2}

Descrição: sem falas. As imagens mostram o marido feliz acariciando a barriga da mulher, o que indica que ela está grávida de novo.

\section{Descrição da produção de sentido das cenas 1 e 2}

S1 - Ela está grávida.

S2 - Ela conseguiu convencer o marido a ter outro filho. 


\section{Cena 3}

Ato de fala 1 (filho): Mãe, já te falei que eu não vou nesse casamento nem a pau.

\section{Cena 4}

Descrição: sem falas. As imagens mostram a mãe e o filho sorridentes assentados entre os convidados de um casamento.

\section{Descrição da produção de sentido das cenas 3 e 4}

S1 - Eles foram ao casamento.

S2 - A mãe conseguiu convencer o filho a ir ao casamento.

\section{Cena 5}

Ato de fala 1 (chefe): Férias? Ahahahahaha...

\section{Cena 6}

Descrição: sem falas. As imagens mostram a mulher e o marido vestidos de roupões em um quarto em Paris.

\section{Descrição da produção de sentido das cenas 5 e 6}

S1 - Ela está em férias, ou não está trabalhando.

S2 - Ela conseguiu convencer o chefe a lhe dar férias.

\section{Cena 7}

Ato de fala 1: As mulheres têm poderes. O poder de limpeza Tixan Ypê é um deles.

\section{Descrição da produção de sentido da cena 7}

S1 - As mulheres têm mais de um poder. A limpeza proporcionada por Tixan Ypê é um tipo de poder.

S2 - Limpar usando Tixan Ypê é um poder das mulheres.

\section{Todas as cenas têm como fundo a música tema da Pantera cor-de-rosa.}

Tabela 1 - Descrição das cenas enunciativas da publicidade de Tixan Ypê.

Ao analisar os atos de fala acima, bem como a descrição das cenas em que aparecem apenas imagens e a música supracitada, percebe-se que a pressuposição é explorada pelo publicitário como forma de atingir seu objetivo comunicativo: anunciar o produto, mostrando os poderes da mulher, especificamente os de persuadir e de conseguir roupas limpas com eficácia. 
Nota-se que há, entre as cenas, uma lacuna de materiais linguísticos que é preenchida pelas provocações imagéticas, desencadeando a pressuposição. Quando, por exemplo, é apresentada, após a sentença proferida pelo marido "Ter outro filho? Agora? Não, né?!", a imagem do marido feliz acariciando a barriga da esposa gestante suprime a linguagem verbal, assim, pressupõe-se que a esposa havia dito ao marido o desejo de ter mais um filho e que ela conseguiu persuadi-lo disso. Essas provocações são, em outras palavras, sugestões (FREGE, 1978, p.66) ou pistas dadas pelo enunciador para estabelecer e evocar no público-alvo as representações que se tem do que fora enunciado na publicidade.

Nessa perspectiva, conforme afirma Sallers (1954), o sentido de que a mulher conseguiu convencer o marido é validado, na medida em que reconhecemos a pressuposição $\left(\mathrm{S}^{2}\right)$ como tendo um valor-verdade.

As três publicidades ora propostas utilizam alguns recursos na tentativa de alcançar a adesão dos telespectadores para adquirir o produto. Citamos dois destes recursos: a afirmação do produto, a certeza, pois o contrário coloca em xeque o mesmo, e dessa forma, comprometeria a persuasão. Outro recurso que aparece nas três publicidades é a repetição da palavra "poder", no início, meio e término das mesmas, realçando- a, possibilitando a aceitação de Tixan por meio da constante reiteração de referentes textuais. Vejamos isso na publicidade 2: O poder da mulher de persuasão (primeira aparição); as mulheres têm poderes (segunda aparição); o poder de limpeza da Tixan Ipê é um deles (terceira aparição); Tixan Ipê, poderoso como você (quarta aparição).

Aqui, podemos verificar também uma herança simbolista em relação à rima, por meio da segunda e terceira aparição da repetição de poder e poderes. Em as mulheres têm poderes (segunda aparição); o poder de limpeza da Tixan Ipê é um deles (terceira aparição) há a presença de uma rima rica, isto é, rimas existentes entre palavras de classes gramaticais diferentes: poderes e deles. Podemos observar que, possivelmente, a rima neste corpus não intenta apenas à repetição de fonemas equivalentes, mas que possui também uma relação semântica. Podemos também notar a repetição da marca Tixan Ipê, na tentativa de fazer com que o consumidor não se esqueça do produto quando for fazer as suas compras. 
A rima era e é tida como um artifício de memorização nas publicidades, e os poetas tiveram grande contribuição conforme Branco, Martensen e Reis (1990):

\begin{abstract}
O público (...) encontrava nas rimas a indispensável ajuda mnemônica para guardar temas e anúncios (era o que os anunciantes desejavam, por isso buscavam os poetas). Enfim, eles dessacralizaram o produto. Inteligentes, descontraídos, de certo modo anteciparam o ângulo do consumidor. Casemiro de Abreu fez graça, Lopes Trovão fez paródia, Olavo Bilac fez sátira. Batendo na tecla alegre, divertida, lançaram a semente do que talvez mais distinga a propaganda brasileira: o seu tom irreverente. (Branco, Martensen e Reis, 1990, p. 3).
\end{abstract}

Tixan é tido como um dos poderes da mulher, assim como os de ler pensamentos, de persuasão, de multiplicação. Duas das pressuposições podem ser observadas: a de que Tixan é para as mulheres; e que o Tixan tem poderes especiais que os outros não têm.

No arcabouço teórico, no que se tratava da verdade e falsidade das afirmações em S1 e S2, dissemos que iríamos retomar sobre as reflexões de STRAWSON (1952) e Mari (2015) para elucidar mais um dos enunciados da publicidade 3 "Tixan Ipê apresenta: o poder da mulher de multiplicação". Assim, abaixo podemos observar que ao dizer o enunciado S, pressupõe S1 e S2.

$S=$ O poder da mulher de multiplicação.

$\mathrm{S} 1=$ Os homens não têm poderes de se multiplicarem. (PP)

$\mathrm{S} 2$ = As mulheres têm poderes além do Tixan Ypê. (PP)

A publicidade nos coloca, com clareza, o papel que a mulher moderna assumiu na sociedade: uma mulher multifacetária - mãe, esposa, trabalhadora. O produto Tixan Ipê revela se tratar de algo inovador que venha contribuir e agregar a ela mais um poder. A publicidade mostra que a mulher já tem poderes, adquiridos por natureza, como a de desempenhar pluritarefas trabalhar e cuidar dos filhos/casa/esposo. Assim é pontuado sobre os desdobramentos da mulher contemporânea, que só serão realizados com maior êxito utilizando os produtos da marca Tixan Ipê. 
Retomemos aos enunciados de cada publicidade:

Publicidade 1: Tixan Ipê apresenta: o poder da mulher de ler pensamentos;

Publicidade 2: Tixan Ipê apresenta: o poder da mulher de persuasão;

Publicidade 3: Tixan Ipê apresenta: o poder da mulher de multiplicação.

A partir dos mesmos, podemos notar que há a presença do artigo definido "o" precedido de "poder" em cada uma delas. Como ilustrado anteriormente, nessas construções, o artigo concede à palavra posterior "poder" o sentido de evento mais importante, não é um mero poder, mas sim o poder que o produto oferece. Assim, o substantivo "poder" está determinado, sugere que o termo posterior a ele é único dentre todos os outros, e é justamente essa proposta da publicidade, tornar o produto Tixan exclusivo, singular. Ademais, o artigo funciona aqui como marcador de pressuposição na medida em que seu uso faz supor a existência anterior de outro produto de similar função, que talvez não seja tão eficiente quanto o anunciado.

No enunciado "sem você pagar mais" o produto Tixan agrega todas as características de um produto de qualidade sem que tenha que pagar a mais por isso, o que pressupõe uma comparação a outras marcas, que para ter mais qualidade e a cada produto lançado, o consumidor paga por isso. Assim, o advérbio de intensidade "mais" participa da persuasão na medida em que convence o consumidor de que não pagará além do que é justo. Assim, a persuasão age com a ajuda desse advérbio que marca a pressuposição. Se a mulher não quiser pagar a mais terá que utilizar Tixan, e como demonstrado acima, se destacar perante as outras mulheres.

As três publicidades da Tixan pressupõem que as mulheres são dotadas de poderes, dentre eles, o de ler pensamentos. Podemos assinalar que nestas três publicidades, a mulher não é abordada como o "sexo frágil", ao contrário, a mulher de muitos poderes. Assim como a mulher tem poder de ler pensamento, pois, quando a filha diz "Mãee", e a resposta é "Pode!", já se pressupõe que a filha ia pedir algo. Dessa forma, a Tixan "leu" os pensamentos das mulheres e de suas necessidades para lavar as roupas "com enzimas ativas ele remove toda a sujeira deixando as roupas limpas e perfumadas sem você pagar mais", 
e criou um produto que as mulheres gostariam e pensavam em ter. As três publicidades do Tixan exploram a pressuposição para provocar o efeito de sentido pretendido em cada uma das peças.

Ao observarmos a música que está por detrás das publicidades, notamos tratar da Pantera Cor de Rosa, de Henry Mancini, tema original de abertura da clássica série animada The Pink Panther. É uma música instrumental, que desperta a atenção para a narratividade da publicidade.

A conjugação da música com as cenas, que já desde o início insinua tratar-se de um espetáculo (Tixan Ipê apresenta), convida o telespectador a contemplar o espaço cenográfico. O telespectador ouve, mesclada as ações da mulher - deixar o bolo pronto à bancada; permitir à saída da filha; enviar mensagem de texto ao marido (publicidade 1); persuadir o marido, filho e 0 patrão (publicidade 2); desempenhar várias funções (publicidade 3), a música $A$ Pantera Cor de rosa, de Henry Mancini. A melodia e o ritmo, marcados e cadenciados, podem ser visualizados nos movimentos corporais e faciais dos personagens das três publicidades. Em determinado ponto da música, há uma nota dissonante, ou seja, as notas não se fundem numa harmonia perfeita quanto às anteriores, que leva o telespectador a presumir que a música e, consequentemente, a publicidade não se conclui, mantendo-a em suspensão, para depois retomar com a parte mais relevante da publicidade, que é o anúncio do produto e de suas vantagens.

A publicidade 3 , a da multiplicação, ao ritmo da música, o esposo evidencia surpresa ao ver a sua mulher na lavanderia. Neste instante, uma pausa da reprodução sonora e, concomitantemente, o personagem-esposo pára e demonstra um estado de alerta e surpresa, e que, provavelmente, o telespectador possivelmente poderá experimentar uma sensação de expectativa e suspense que talvez não fosse tão sensivelmente percebido sem a sugestão musical. Mais uma vez, verifica-se aqui um jogo de tensões: as tensões rítmico-melódicas conjugadas com as tensões do movimento espacial e da expressão corporal e facial do ator, proporcionando sugestões de imagens rítmicas e de emoções.

Em relação ao exposto acima, ao estado de surpresa do esposo na publicidade 3 , podemos perceber que a peça publicitária sugere que se fosse outra mulher observando a esposa na lavanderia não haveria surpresa, 0 
efeito de sentido não seria o mesmo, haja vista que, conforme notado no corpus em análise, todas as mulheres executam de forma notável seus afazeres e, que portanto, só a elas o poder é atribuído. O homem se assusta, pois para ele o fato de realizar várias tarefas, simultaneamente, parece ser impossível, o que aqui pode-se pensá-lo como o "sexo frágil". Talvez a mensagem que a publicidade tenta nos passar é a de que somente as mulheres possuem esse papel multifacetário, e que este produto, certamente, ajudará em mais uma de suas tarefas.

No enunciado "Tixan Ipê: poderoso como você" pressupõe uma verdade instaurada pela instância de produção, a de que utilizar o produto é o mesmo que estar determinado para o sucesso e para o triunfo - ler pensamentos; poder de persuasão e poder de multiplicação. O convite para o uso do produto soa como obrigação. A mulher que coloca em prática o que se profere na publicidade, isto é, utiliza o produto Tixan se diferenciará das outras mulheres as que utilizam o produto das outras que não utilizam. Além disso, o Tixan Ypê está associado ao consumo consciente, o que faz dele ser considerado ainda mais vantajoso. Entre diferentes marcas, a Tixan ocupou uma das primeiras colocações quanto a esse quesito1. Para o levantamento, os consumidores foram indagados sobre o empreendimento que estaria atrelado ao consumo consciente. Dentre as empresas mais referidas estava a Tixan Ipê. Mais uma vez, a Tixan tenta mostrar a liderança de seu produto.

\section{À GUISA DE CONCLUSÃO}

É inegável o poder exercido pela mídia e sua importância na vida da coletividade humana. Deixamo-nos envolver pela linguagem e sua consequente maneira de transmitir as informações pelo canal televisivo. A televisão desenvolve formas sofisticadas de comunicação sensorial, emocional e racional, integrando imagens e músicas que fazem mexer com os sentimentos das pessoas.

O repertório de informações requer linguagens mais variadas e criativas. É pela aglutinação da linguagem verbal discursiva com as linguagens sonora e visual que poderemos encontrar uma nova forma de pensar o mundo que nos 
cerca. Aliada às linguagens verbais, tem-se a musicalidade nas três publicidades, que produzem um efeito, estratégia para captar ainda mais a atenção do telespectador. O poder de persuasão das publicidades ora analisadas está no conjunto de signos apresentados, combinando linguagens diversas.

Conforme a hipótese aventada no início deste trabalho, constatamos que a pressuposição é explorada nas publicidades da Tixan de modo premeditado, isto é, a categoria não é tomada de forma ingênua, e sim proposital. Como os conteúdos semânticos são culturalmente partilhados e se relacionam ao não dito, podemos dizer que a pressuposição se configura como uma arma nas mãos da instância de produção, compondo uma rede semântica na tentativa de influenciar no consumo do produto.

\section{${ }^{1}$ http://consumidormoderno.uol.com.br/impressas/CM182.pdf}

Além do objetivo basilar, que é a venda do produto, a publicidade direcionada ao público-alvo (o feminino) reflete padrões sociais, bem como cria modelos novos, que dialogam com os ideais desse público-consumidor. Vale salientar que a mulher protagonizada pela publicidade Tixan Ipê trata-se de uma mulher contemporânea, moderna, que desempenha vários papéis e que, portanto, tem suas necessidades, uma delas a de ter um produto que facilite a sua vida. Constatamos por meio das três publicidades que o produto Tixan Ipê utilizado pela mulher moderna se transforma de forma a atender às suas necessidades, que fortalece o conceito da família perfeita, o que torna mais um elemento de persuasão para adquirir o produto.

A pressuposição, nesse sentido, está fortemente presente no discurso publicitário e, a partir dela, o interlocutor é levado a construir o sentido que reafirma a ideia central de cada peça publicitária. Isso incide, portanto, sobre a persuasão, à medida que relaciona a mensagem da publicidade com as qualidades do produto Tixan. 
Ademais, o que está por detrás das peças publicitárias é a criação de um mundo perfeito para as mulheres, onde o produto anunciado oferece às mulheres um poder sobrenatural que é visto somente aqui. Além de fazer com que as mulheres entrem nesse universo de crenças, intenta-se que elas reconheçam o ambiente do qual desejam fazer parte - e que somente farão se utilizarem o produto da Tixan. Por fim, o que a marca faz é diferenciar seu produto, na tentativa de destacá-lo do lugar comum, utilizando uma linguagem de sedução.

\section{REFERÊNCIAS}

BRANCO, Renato Castelo; MARTENSEN, Rodolfo Lima; REIS, Fernando. Os intelectuais e a propaganda. In: Jorge Medauar. História da Propaganda no Brasil. São Paulo: T. A. Queiroz, 1990. v.21. p7-20.

CARVALHO, Nelly de. Publicidade, a linguagem da sedução. 3. ed. São Paulo: Ática, 2003.

DUCROT, Oswald. O dizer e o dito. Campinas: Pontes, 1978.

DUCROT, Oswald. Princípios de semântica linguística. São Paulo: Cultrix, 1972.

FREGE, G. Lógica e filosofia da linguagem. São Paulo: Cultrix, 1978.

KEENAN, E. Two kinds of presupposition in natural language. FILLMORE, C. \& LANGENDOEN, D. (Org.) Studies in Linguistic Semantics. New York: Holt, Rinehart and Winston, 1971.

KOCH, Ingedore. Argumentação e Linguagem. $7^{\text {a }}$ ed. São Paulo, Cortez, 2002. 
MARI, Hugo. Conceitos de pressuposição: histórico. Disponível em: $<$ http://www.ich.pucminas.br/posletras/SEMANTICAconceitos_de_pressuposicao.pdf>Acesso em: 13 jan. 2015. 